\title{
IMPLEMENTASI SISTEM PENDAFTARAN DAN EDUKASI PENCAK SILAT BUDI ASIH SE-CIAYUMAJAKUNING BERBASIS WEBSITE DENGAN FRAMEWORK CODEIGNITER (CI)
}

\author{
Ahmad Lubis Ghozali ${ }^{1}$, Kurnia Adi Cahyanto ${ }^{2}$, Diky Anwar ${ }^{3}$ \\ ${ }^{1,2,3}$ Program Studi Teknik Informatika, Politeknik Negeri Indamayu, Jawa Barat, Indonesia \\ ${ }^{1}$ lubis@ polindra.ac.id, ${ }^{2}$ kelixo@gmail.com, ${ }^{3}$ dicky.salju@gmail.com
}

\begin{abstract}
ABSTRAK
Tertutupnya akan informasi mengenai pencak silat akhirnya membuat pencak silat sebagai warisan budaya bangsa Indonesia hilang tergerus perkembangan jaman dengan adanya teknologi yang semakin modern seperti saat ini. Biasanya pendaftaran pada perguruan pencak silat Budi Asih masih menggunakan cara konvensional, yaitu anggota baru harus memperoleh formulir pendaftaran, mengisi data, dan menyerahkannya ke Guru kolatnya atau Sekretariat. Masalah pendaftaran dan edukasi bisa dilakukan dengan solusi aplikasi pencak silat Budi Asih berbasis website sehingga prosesnya menjadi lebih cepat jika dibandingkan dengan cara konvensional. Hasil dari pengujian yang dilakukan oleh pengguna untuk mencoba aplikasi ini menunjukkan bahwa dapat mempercepat kerja pengurus secretariat dalam mengolah data secara terkomputerisasi.
\end{abstract}

Kata Kunci: Aplikasi website, framework Codeigniter, Pencak Silat, Silat Cirebon.

\begin{abstract}
The closure of information about pencak silat finally made pencak silat as a cultural heritage of the Indonesian nation disappear eroded by the development of the era with the increasingly modern technology as it is today. Usually registration at the Budi Asih Pencak Silat College still uses the conventional way, ie new members must obtain a registration form, fill in the data and submit it to the Kolat teacher or the Secretariat. The registration and education problems can be done with the website-based pencak silat silat application solution so that the process is faster when compared to conventional methods. The results of tests conducted by users to try this application show that it can speed up the work of the secretariat in processing computerized data when compared with conventional methods.
\end{abstract}

Keywords: Website based application, framework Codeigniter, Pencak Silat, Silat Cirebon. 


\section{PENDAHUluaN}

Pencak silat atau silat (berkelahi dengan menggunakan teknik pertahanan diri) merupakan seni beladiri Asia yang berakar dari budaya Melayu. Seni beladiri ini secara luas dikenal di Indonesia, Brunei, dan Singapura. Berkat peranan para pelatih silat asal Indonesia, saat ini Vietnam juga memiliki pesilat-pesilat yang tangguh. Di Indonesia untuk mewadahi organisasi dari berbagai perguruan pencak silat dibentuklah induk organisasi pencak silat yaitu IPSI (Ikatan Pencak Silat Indonesia) didirikan pada tanggal 18 Mei 1948 di Surakarta, Jawa Tengah.

Pencak silat yang mengutamakan beladiri sebetulnya sejak dahulu sudah ada karena dalam mempertahankan hidupnya manusia harus bertempur, baik manusia melawan manusia maupun manusia melawan binatang buas. Pada waktu itu orang yang kuat dan pandai berkelahi mendapat kedudukan yang baik di masyarakat sehingga dapat menjadi kepala suku atau panglima raja. Lambat laun ilmu berkelahi lebih teratur sehingga timbulah suatu ilmu beladiri yang disebut pencak silat (Mulyana, 2013: 79).

Dengan maksud turut melestarikan budaya bangsa Indonesia dan sebagai wahana menyiapkan pesilat-pesilat yang berjiwa pancasila serta UUD 1945 dan rela berkorban bagi kehormatan bangsa dan Negara, atas berkat rahmat Allah yang maha esa maka didirkan perguruan pencak silat Budi Asih pada tanggal 4 November 1981 di Desa Kejuden Kecamatan Plumbon Kabupaten Cirebon oleh Abah Ali Maksudi. Perguruan pencak silat Budi ASih dipengaruhi oleh beberapa aliran diantaranya yaitu: aliran Cimande, Cikalong, Pamonyet, dan Depok.

Diera modern seperti sekarang ini pencak silat sebagai warisan budaya asli dari bangsa Indonesia menjadi kurang begitu diminati. Tertutupnya informasi mengenai pencak silat akhirnya membuat pencak silat sebagai warisan budaya bangsa hilang tergerus perkembangan jaman dengan adanya teknologi yang semakin modern ini. Jika hal ini dibiarkan begitu saja maka yang akan terjadi adalah pencak silat hanya menjadi cerita sejarah bangsa Indonesia tanpa ada generasi muda yang ingin untuk melestarikannya.

Dalam upaya untuk terus berperan serta melestarikan dan mengembangkan warisan budaya banga Indonesia serta menyelesaikan permasalahan yang dibutuhkan oleh perguruan pencak silat Budi Asih, maka dibuatlah sebuah rancang bangun sistem pendaftaran dan edukasi pencak silat Budi Asih se-Ciayumajakuning yang dengan adanya aplikasi ini bisa melakukan pendaftaran anggota, pembelajaran teknik beladiri, mempermudah pesilat untuk menjadi atlet baik ditingkat daerah, nasional, dan internasional, serta mengetahui informasi pencak silat Budi Asih melalui aplikasi ini. Maka berawal dari permasalahn tersebut menjadi alasan utam bagi penulis untuk memilih judul Penelitian ini.

\section{TINJAUAN PUSTAKA}

\subsection{Pengertian Sistem}

Menurut Tata Sutabri [1] pada dasarnya sistem adalah sekelompok unsur yang erat hubungannya satu dengan yang lain, yang berfungsi bersama-sama untuk mencapai tujuan tertentu. James A. Hall [2] memaparkan bahwa sistem adalah sebuah kelompok dari dua atau lebih komponen yang saling berhubungan atau subsistem untuk mencapai tujuan bersama. Dari definisi diatas, dapat disimpulkan bahwa sistem adalah komponen-komponen yang saling berkaitan dan bekerjasama untuk mencapai suatu tujuan tertentu.

\subsection{Pengertian Rancang Bangun}

Menurut Jogiyanto [3] menjelaskan bahwa perancangan sistem dapat didefinisikan sebagai gambaran, perencanaan, dan pembuatan, sketsa, atau pengaturan dari beberapa elemen yang terpisahkan kedalam satu kesatuan yang utuh dan berfungsi. Tujuan dari perancangan sistem yaitu untuk memenuhi kebutuhan para pemakai sistem dan memberikan gambaran yang jelas dan rancang bangun yang lengkap kepada programmer. Kedua tujuan ini lebih focus pada perancangan atau desain sistem yang terinci yaitu pembuatan rancang bangun yang jelas dan lengkap yang nantinya akan digunakan untuk pembuatan program komputer.

\subsection{Pengertian Edukasi}

Menurut Notoadmojo [4] menjelaskan bahwa edukasi atau disebut juga dengan pendidikan merupakan segala upaya yang direncakan untuk mempengaruhi orang lain baik individu, kelompok, atau masyarakat sehingga mereka melakukan apa yang diharapkan oleh pelaku pendidikan.

\subsection{Formula}

Website adalah sebuah tempat yang menyediakan beragam halaman informasi untuk dapat diakses melalui internet. Website sendiri dari 9 macam komponen, seperti gambar, animasi, video, teks, dan lain sebagainya. Hal inilah yang membuat sebuah website banyak dikunjungi orang-orang untuk mendapatkan sebuah informasi. Melalui website, kita bisa mempublikasikan apa saja kreativitas kita yang kita bisa. Dengan begitu, peranan website sangatlah banyak untuk kita semua. Akan tetapi, tak sedikit orang yang masih belum paham mengenai website, unsur-unsur pada website dan jenis website. Namun, setelah membaca penjelesan ini mengenai pengertian website bisa membuka mata anda untuk mendapatkan informasi lengkap mengenai website itu sendiri. Jika disimpulkan, website adalah sebuah wadah atau media yang menampung beragam informasi untuk disampaikan kepada khalayak umum. 
Jurnal Ilmiah Ilmu Komputer Vol. 5, No. 2, September 2019

Fakultas Ilmu Komputer

Universitas AL Asyariah Mandar

\subsection{Formula}

Codeigniter adalah sebuah framework PHP yang dapat membantu mempercepat developer dalam pengembangan aplikasi web berbasis PHP dibandingkan jika menulis semua kode program dari awal. Codeigniter didasarkan pada pola pengembangan model-view-controller (MVC).

Ada beberapa bagian-bagian dari MVC, diantaranya yaitu sebagai berikut:

a. Model

Berisi fungsi-fungsi yang dapat digunakan untuk mengelola database seperti add, edit, delete, dan sebagainya.

b. View

Yang mengatur tampilan halaman website. Bagian inilah yang bertugas unutk mempresentasikan data kepada user. Video berbentuk struktur HTML yang berisikan variable data yang dikirimkan oleh Controller.

c. Controller

Merupakan bagian yang berfungsi sebagai penghubung antara model dan view. Controller berisi fungsi-fungsi untuk memproses suatu data. Codeigniter memungkinkan untuk memasukkan script yang dibuat sendiri atau bahkan mengembangkan library inti untuk sebuah sistem.

\section{METODOLOGI PENELITIAN}

\subsection{Metode Penelitan}

Metode yang digunakan untuk mengetahui alur penelitan dan pembuatan sistem. Memiliki beberapa tahapan dalam prosesnya, Untuk lebih jelasnya dapat dilihat pada gambar 3.1 Metodologi Penelitian ini.

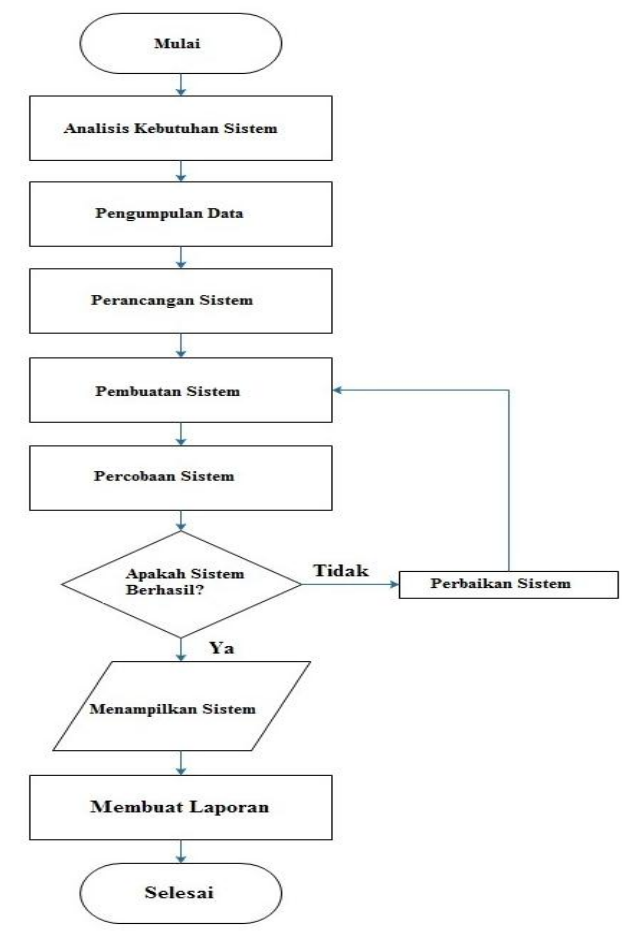

Gambar 3.1 Metode Penelitian
(P) ISSN 2442-451X

(O) ISSN 2503-3832

\subsection{Analisis Kebutuhan Sistem}

Berdasarkan hasil kebutuhan sistem terdapat kebutuhan dalam bentuk hardware (perangkat keras) dan software (perangkat lunak).

\subsubsection{Kebutuhan Hardware (Perangkat Keras)}

Berdasarkan kebutuhan hardware yang mampu untuk mendukung implementasi sistem. Memiliki beberapa kebutuhan diantaranya:

Tabel 3.1 Daftar kebutuhan Hardware

\begin{tabular}{|l|l|l|}
\hline No & Jenis Hardware & Kebutuhan Hardware \\
\hline 1 & Laptop / PC & Intel / AMD \\
\hline 2 & Prosessor & $1.65 \mathrm{GHz}$ up to above \\
\hline 3 & RAM & $2 \mathrm{~GB}$ up to above \\
\hline 4 & Harddisk & 500 up to above \\
\hline
\end{tabular}

\subsubsection{Kebutuhan Software (Perangkat Keras)}

Berdasarkan kebutuhan software yang mampu untuk mendukung implementasi sistem. Memiliki beberapa kebutuhan diantaranya:

Tabel 3.2 Daftar kebutuhan Software

\begin{tabular}{|l|l|l|}
\hline No & Jenis Hardware & Kebutuhan Hardware \\
\hline 1 & Laptop / PC & Intel / AMD \\
\hline 2 & Prosessor & $1.65 \mathrm{GHz}$ up to above \\
\hline 3 & RAM & $2 \mathrm{~GB}$ up to above \\
\hline 4 & Harddisk & 500 up to above \\
\hline
\end{tabular}

\subsection{Activity Diagram}

Berdasarkan activity diagram dapat melihat berbagai aktivitas secara jelas apa-apa saja yang dilakukan oleh user pada saat menggunakan aplikasi.

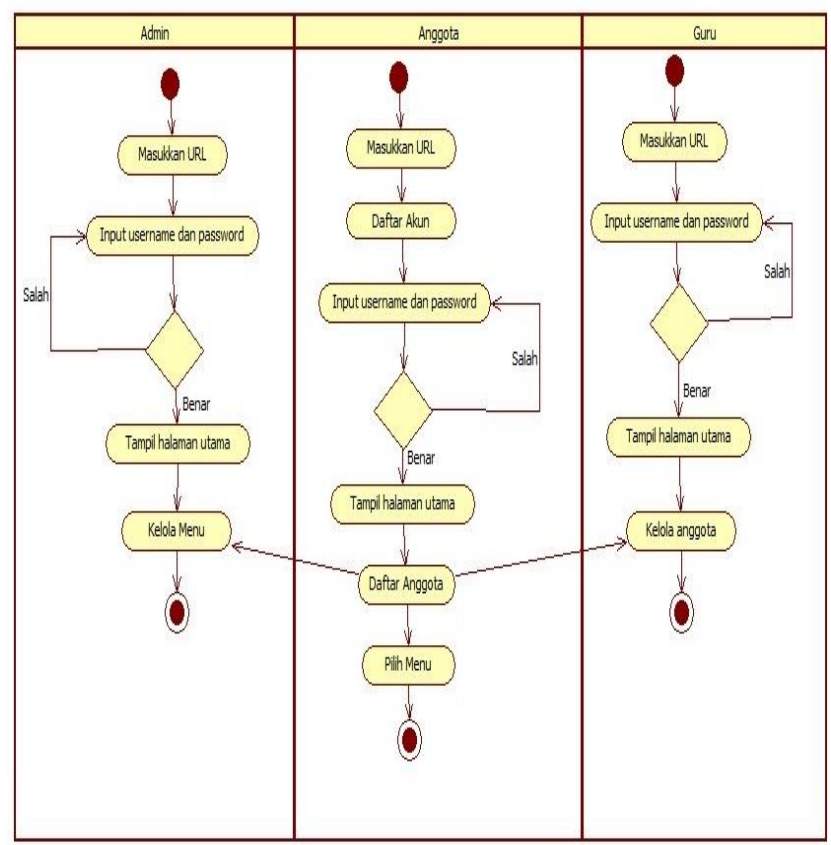

Gambar 3.2 Activity Diagram User 


\section{HASIL DAN PEMBAHASAN}

\subsection{Hasil Penelitian}

Ada beberapa kegunaan dari adanya aplikasi ini yaitu diantaranya sebagai berikut:

1. Untuk mempercepat pekerjaan guru silat dimasingmasing kelompok latihan dengan cara terkomputerisasi yaitu memberi tahu pada anggota baru di kelompok latihannya supaya mendaftar melalui aplikasi pencak silat Budi Asih karena data anggota baru akan langsung masuk ke admin di Padepokan;

2. Guru atau admin yang berada di padepokan silat lebih mudah dalam menyampaikan informasi kepada anggota dan Guru kolat. Dengan adanya informasi itu akan langsung tersampaikan ke tiap-tiap kelompok latihannya yang berada di wilayah III Cirebon;

3. Anggota bisa mengunduh modul ajar melalui aplikasi pencak silat Budi Asih yang dapat diakses dimanapun dan kapanpun secara online.

\subsection{Hasil Pengujian}

Berikut ini rangkuman dari prosedur pengujian yang telah penulis lakukan. Untuk lebih jelasnya silahkan perhatikan tabel dibawah ini.

Tabel 4.1 Rangkuman hasil pengujian Black Box

\begin{tabular}{|c|c|c|}
\hline No & Deskripsi & Kesimpulan \\
\hline 1 & Login Multilevel & $\begin{array}{l}\text { Fungsi pada login } \\
\text { multilevel sudah berfunsi } \\
\text { sesuai dengan yang } \\
\text { diharapkan }\end{array}$ \\
\hline 2 & Admin & $\begin{array}{l}\text { Fungsi pada admin sudah } \\
\text { berfungsi sesuai dengan } \\
\text { yang diharapkan }\end{array}$ \\
\hline 3 & Guru Kolat & $\begin{array}{l}\text { Fungsi pada Guru kolat } \\
\text { sudah berfungsi sesuai } \\
\text { dengan yang diharapkan }\end{array}$ \\
\hline 4 & Anggota & $\begin{array}{l}\text { Fungsi pada anggota kolat } \\
\text { sudah berfungsi sesuai } \\
\text { dengan yang diharapkan }\end{array}$ \\
\hline 5 & Informasi & $\begin{array}{l}\text { Fungsi pada informasi } \\
\text { kolat sudah berfungsi } \\
\text { sesuai dengan yang } \\
\text { diharapkan }\end{array}$ \\
\hline 6 & SPP Anggota & $\begin{array}{l}\text { Fungsi pada SPP anggota } \\
\text { kolat sudah berfungsi } \\
\text { sesuai dengan yang } \\
\text { diharapkan }\end{array}$ \\
\hline 7 & Evaluasi & $\begin{array}{l}\text { Fungsi pada evaluasi } \\
\text { sudah berfungsi sesuai } \\
\text { dengan yang diharapkan }\end{array}$ \\
\hline 8 & Struktur Pengurus & $\begin{array}{l}\text { Fungsi pada struktur } \\
\text { pengurus sudah berfungsi } \\
\text { sesuai dengan yang } \\
\text { diharapkan }\end{array}$ \\
\hline 9 & Buku Tamu & $\begin{array}{l}\text { Fungsi pada buku tamu } \\
\text { sudah berfungsi sesuai } \\
\text { dengan yang diharapkan }\end{array}$ \\
\hline
\end{tabular}

\section{KESIMPULAN DAN SARAN 5.1 Kesimpulan}

Setelah dilakukan penelitian, perancangan, implementasi, dan pengujian pada Penelitian ini. Penulis telah berhasil membuat rancang bangun sistem pendaftaran dan edukasi pencak silat Budi Asih se-Ciayumajakuning berbasis website dengan framework codeigniter. Untuk membangun aplikasi ini penulis menggunakan database untuk menyimpan data serta untuk aplikasi bisa diakses secara online disemua browser. Maka dengan itu penulis dapat mengambil beberapa kesimpulan sebagai berikut:

1. Perancangan aplikasi UML yang terdiri dari use case diagram, activity diagram, sequence diagram, dan class diagram serta terdapat flowchart terdiri dari flowchart program dan sistem;

2. Pada pembuatan aplikasi terdiri dari 3 antarmuka yaitu admin, Guru kolat, dan anggota yang memiliki menu yang berbeda-beda dan;

3. Implementasi pada aplikasi memiliki beberapa fitur untuk proses pelayanan pendaftaran dan edukasi anggota menjadi lebih cepat apabila dibandingkan cara konvensional.

\subsection{Saran}

Berdasarkan kesimpulan penelitian, berikut beberapa saran yang dapat penulis sampaikan sebagai pengembangan lebih baik ke depannya yaitu:

1. Perlu adanya pemahaman UML dan flowchart agar admin, Guru kolat, dan anggota memahami dan dapat mengoperasikan aplikasi dengan baik dan benar;

2. Aplikasi yang telah dibuat bisa dikembangkan kembali menggunakan platform lain agar proses pelayanan pendaftaran lebih cepat daripada menggunakan manual kertas;

3. Fitur yang telah ada dapat dikembangkan kembali dengan tujuan supaya proses pelayanan pendaftaran lebih cepat daripada menggunakan cara konvensional;

4. Pada fitur notifikasi pesan masuk masih by refresh dan belum realtime.

\section{DAFTAR PUSTAKA}

[1] Hakim, Lukmanul. 2010. Membangun Web Berbasis PHP dengan Framwork Codeigniter. Yogyakarta: Lokomedia.

[2] Ismantohadi, Eka. 2014. Modul Rekayasa Perangkat Lunak. Indramayu: Politeknik Negeri Indramayu.

[3] Mulyana. 2013. Pendidikan Pencak Silat: Membangun Jati Diri dan Karakter Bangsa. Bandung: PT Remaja Rosdakarya.

[4] Mulyanto, Agus. 2009. Sistem Informasi Konsep dan Aplikasi. Yogyakarta: Pustaka Pelajar. 
Universitas AL Asyariah Mandar

[5] Pressman, Roger. 2012. Rekayasa Perangkat LunakBuku Satu, Pendekatan Praktisi (Edisi 7). Yogyakarta: Andi.

[6] Raharjo, Budi. 2015. Belajar Otodidak Framework Codeigniter. Bandung: Balai Pustaka.

[7] Sutabri, Tata. 2012. Analisis Sistem Informasi. Yogyakarta: Graha Ilmu. 